\title{
Research Paper: Development of Word Definition Skill in Persian-speaking 54-90-month-olds
}

\author{
Maryam Malekian' $^{1}$ (D), Talieh Zarifian ${ }^{1^{*}}$ (D), Robab Teymouri² (D) \\ 1. Department of Speech Therapy, University of Social Welfare and Rehabilitation Sciences, Tehran, Iran. \\ 2. Pediatric Neurorehabilitation Research Center, University of Social Welfare and Rehabilitation Sciences, Tehran, Iran.
}

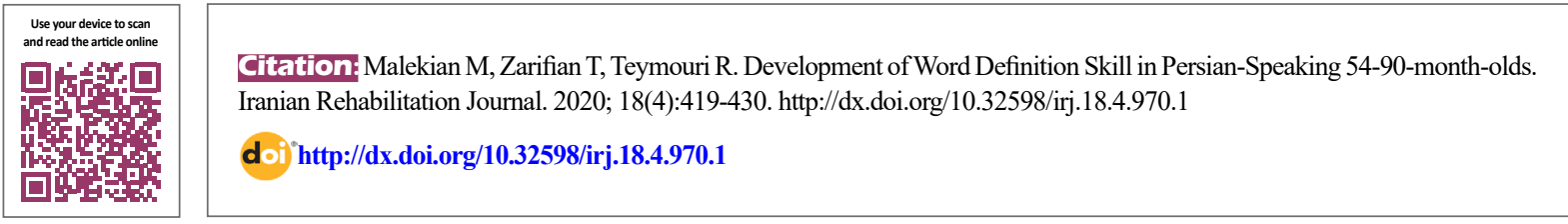

Article info:

Received: 28 Oct 2019

Accepted: 18 Nov 2020

Available Online: 01 Dec 2020

\section{Keywords:}

Development, Word definition, Child, Semantic

\section{ABSTRACT}

Objectives: Word definition skill is a complex language ability in which meta-linguistic awareness and literacy skills play a critical role. The present study examined the development of word definition skills in Persian-speaking children aged 4.5 to 7.5 years, concerning content and form aspects.

Methods: This was a cross-sectional and analytic-descriptive study. The study subjects were 107 children of three age groups, as follows: 54-65-month-olds, 66-77-month-olds, and 78-90-month-olds. The study participants were selected from kindergartens and schools in districts 1, 7, and 17 of Tehran City, Iran, by multi-stage sampling method. In the word definition task, children were requested to define the words. To analyze the obtained data, the Kruskal-Wallis test was used.

Results: The obtained results indicated that the mean score of content $(\mathrm{P}=0.001)$ and form $(\mathrm{P}=0.002)$ aspects of word definition significantly increased with age in the study participants.

Discussion: Ashift from functional and objective responses towards meta-linguistic definitions, i.e. further developed in terms of content and form, was observed with aging. At the age of 7 years, definitions reflect the hierarchical nature of nouns, and applying the class name begins at this age. The age of reaching a specific class seems to be affected by the lexical category. 


\section{Highlights}

- The development of word definition skills in Persian is similar to that in other languages.

- In the content dimension of word definition, pre-school children tend to employ more concrete and functional specifications to express definition. At the age of seven years, definitions reflect the hierarchical nature of nouns.

- In the form dimension of word definition, using non-verbal responses and single-word transitional significantly decreased with aging. Accordingly, the use of full Aristotelian response significantly increased in the study subjects.

\section{Plain Language Summary}

To examine word development and the subsequent changes in conceptual knowledge, the word definition task can be employed. In this task, the individual must define a presented word. In this study, 107 children (54-90 months) were evaluated. They were requested to definite 14 nouns, and their responses surveyed the basis of their content and form. With increasing age, children's use of the single word and functional responses decreased. Besides, applying category names increased with aging.

\section{Introduction}

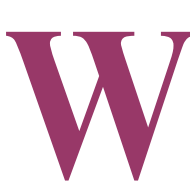

ord knowledge regarding mental lexicon consists of the phonemic knowledge of the sounds in a word; grammatical knowledge of how to use a word in combination with others; and conceptual knowledge, including basic data about words and their definitions [1].

Vygotsky in 1978 proposed the systematic development of word definition, claiming that the conceptual knowledge of the meaning of words changes over the development process. According to him, when the referent of a word becomes substantial, its meaning keeps developing. For example, from a young child's perspective, who has been bitten by a dog, the dog may be considered as a wild animal. However, if the child has always been spending time with the dog and is accustomed to playing with it, the dog is considered to be an adorable pet. Thus, emotional content forms the words' meaning at this stage. Next, awareness becomes objective, and the word "dog" recalls a specific memory (e.g. a dog being fed). As the child ages, the word definition becomes part of a system of abstract oppositions, like "dog is an animal, not a plant" [2]. The development of word meaning and other linguistic aspects continues throughout the school years [3].

The word definition task can be employed to examine the word development and the subsequent changes in conceptual knowledge [2]. In this task, the subject must define a presented word [4]. This task also examines an individual's metalinguistic ability [5]. Metalinguistic abil- ity refers to an individual's awareness of the components that form an acceptable definition; it also addresses one's ability to analyze word classes and their features [4, 6].

Several studies have investigated the word definition skill, specifying its development in healthy children with different languages [7-12]. In a review article, Kikas highlighted qualitative differences between definitions provided by children of different ages. Younger children use descriptive and functional definitions; however, children aged $>9$ years provide more abstract definitions, including the word class [13]. Gavriilidou assessed the word definition skill in Greek preschool children. The relevant results revealed that the objective and functional responses shift towards more conceptual and abstract responses [7]. To et al. studied the word definition skill in Chinese speakers aged 4.10 to 12.01 years. According to their findings, using main features, including the class, increases with age, leading to the generation of more formal definitions [8].

Zarifian et al. investigated the word definition skill in Persian-speaking children aged 7 to 12 years. They concluded that the mean scores of the content and form aspects significantly increased with age $(\mathrm{P}<0.01)$. Moreover, the content aspect of the responses shifted towards combination type II with age. Finally, regarding the form, phrases, clauses, simple sentences, transitional forms, and Aristotelian forms were the most frequent responses in the explored age group [14].

Mohammadi et al. compared the word definition scores in children aged 7-9 years with Developmental Lan- 
guage Disorder (DLD) and healthy Persian-speaking children. The related results indicated children with DLD achieved lower scores in content and form aspects, compared to their healthy counterparts [12].

The development of this skill initiates at the age of 4 years [13]. Furthermore, data on the development of this skill in Persian-speaking children aged $<7$ years are scarce; thus, this research intended to examine the process of developing word definition in 4.5-7.5-year-olds We also aimed to investigate the word definition skill changes with age in Persian-speaking children.

\section{Methods}

The present descriptive-analytical and cross-sectional study investigated 107 children (54 girls and 53 boys) of three age groups. There were 18 girls and 18 boys in the first (54-65 months) and third (78-90 months) age groups. The second age group (66-77 months) included 18 girls and 17 boys. The multi-stage cluster sampling method was used to select the study participants. For sampling, 22 urban districts of Tehran City, Iran, were divided into three development zones (low, medium, and high) in terms of socioeconomic status [15]. After determining the regions located per zone, one of them was randomly selected. Then, two kindergartens, one girl's school, and one boy's school were randomly selected in each region. The inclusion and exclusion criteria of the study included being a monolingual Persian-speaker, the absence of any vision, hearing, and neurological deficits. The lack of any physical impairments, restricting the child's interactions with others, and the absence of any emotional and mental health problems, and any delays in psychomotor, speech, and language development.

The instruments used in this study were a researchermade questionnaire and the word definition task. The researcher-made questionnaire was developed by the researchers to collect the study participants' demographic data and to apply the inclusion and exclusion criteria of the research. The questionnaires and the written consent forms were provided to the parents of the children who had met the inclusion criteria of the study. The children's health records and questionnaires were evaluated in terms of the inclusion and exclusion criteria of the research.

The study subjects were asked about the meaning of each word presented in the word definition task. Each episode of the task normally lasted 15 minutes. After completing the task, children's recorded definitions were transcribed and scored based on the content (Table 1) and form (Table 2) scoring approaches [16].
The word definition task was designed by Mohammadi in 2009. This task contains 14 words of 7 categories, as follows: eating instruments, animals, transportation, body parts, jobs, fruits, and places. The task was developed for children in the first to third grades of elementary school. Inter-rater validity was used to determine the validity of the task concerning the content aspect. The validity obtained for the content aspect in the first and second run was $71 \%$ and $82 \%$, respectively [12]. The scoring method was adopted from Marinellie and Johnson [5].

The task's validity and reliability were re-examined for this age group since the target population consisted of children aged 4.5 to 7.5 years. The task was applied to 10 children aged 54-65 months to determine the ability of children in defining words. It was found that the children of this age group recognized the words and could define them. Inter-rater reliability was used to determine the reliability of the task. Ten children of each age group were randomly selected and a total of 420 responses $(14 \times 30)$ were provided. Spearman correlation coefficient index was calculated as 0.93 for the content aspect. Therefore, the task was valid and reliable for the age group that participated in the current study.

The best definitions provided for each word was scored as 5. A six-point scoring scale, ranging from zero to 5 was employed for the form and content aspects of the task. The maximum and minimum scores per participant defining the 14 words were 70 and zero, respectively. To calculate the frequency of content and form responses, the sum of each response was divided into the total number of responses in the first and third (504), and second, (490) age groups and multiplied by 100 (Tables 3 and 4). Then, the Chi-squared test was used to assess the significance of changes in the study participants' responses (Tables 5 and 6).

The Shapiro-Wilk test data indicated that the variables were not normally distributed; thus, the non-parametric statistical tests were employed. The Kruskal-Wallis test was used (Tables 7 and 8) to investigate the differences in the mean scores of the content and form aspects in different age groups. Additionally, multiple comparison tests were applied to compare the paired mean scores.

\section{Results}

The present study results regarding the development of the content aspect revealed that functional responses were the most frequent feedbacks in all age groups (Figure 1 and Table 3). In the first age group, the most frequent response was concrete, and responses contain- 
ing combination type II had the highest frequency in the second and third age groups. The frequency of error, concrete, and function responses decreased with age. In contrast, the frequency of responses containing combinations type I and type II increased with age. The frequency of class-nonspecific and class-specific responses used by the children of the second age group increased in contrast to that of the children of the first age group; however, the frequency of such responses decreased in the third age group. In contrast, the frequency of responses including combinations type I and type II increased in them. None of the three age groups used synonyms, and the frequency of association and relation responses equaled $<2 \%$.
Reviewing significant changes among the age groups (Table 5), it was observed that using error $(\mathrm{P}=0.002)$ and concrete $(\mathrm{P}=0.003)$ responses significantly decreased; however, the use of combination type II significantly increased $(\mathrm{P}<0.001)$ in them. Concerning other responses, despite some changes, none of them were significant.

In all explored age groups, responses containing clauses, phrases, and simple sentences were of most frequency (Figure 2 and Table 4). Transitional form responses were the second most frequent in all studied age groups. The frequency of non-verbal responses and single words, clauses, phrases, and simple sentences decreased with age; however, the frequency of responses with partialand full-Aristotelian form increased with age. Further-

Table 1. Categories and points assigned for the content of noun definitions

\begin{tabular}{|c|c|c|}
\hline Category & Point(s) & Example(s) \\
\hline $\begin{array}{c}\text { Error } \\
\text { (incorrect definition, no response, or gesture) }\end{array}$ & 0 & $\begin{array}{c}\text { Horse: "like a horse" } \\
\text { Pencil: \{child uses writing gesture }\}\end{array}$ \\
\hline $\begin{array}{l}\text { Function } \\
\text { (the function of the item or how the object is used) }\end{array}$ & 1 & $\begin{array}{l}\text { Book: "you read it" } \\
\text { Horse: "runs fast" }\end{array}$ \\
\hline $\begin{array}{c}\text { Concrete } \\
\text { (composition, color, shape, location, etc.) }\end{array}$ & 1 & Apple: "red and round" \\
\hline Association & 1 & $\begin{array}{c}\text { Baby: "little" } \\
\text { Book: "has lots of pages and words" } \\
\text { Pencil: "paper" } \\
\text { Book: "homework" }\end{array}$ \\
\hline Relation (use of analogy) & 1 & $\begin{array}{l}\text { Horse: "like a cow" } \\
\text { Train: "like a car" }\end{array}$ \\
\hline Class-nonspecific & 2 & $\begin{array}{l}\text { Train: "a kind of machine" } \\
\text { Apple: "a snack" }\end{array}$ \\
\hline Class-specific & 3 & $\begin{array}{l}\text { Horse: "an animal" } \\
\text { Apple: "fruit" }\end{array}$ \\
\hline Synonym & 3 & Book: "text" \\
\hline $\begin{array}{l}\text { Combination I } \\
\text { (Any combination of function, concrete, relation association, and } \\
\text { class-nonspecific) }\end{array}$ & 4 & Apple: "it is red and you eat it as a snack" \\
\hline $\begin{array}{l}\text { Combination II } \\
\text { (The use of class-specific or synonym plus at least one attribute) }\end{array}$ & 5 & $\begin{array}{l}\text { Pencil: "you write with it and } \\
\text { it's made out of wood" } \\
\text { Train: "it is transportation. Trains run on tracks" } \\
\text { Book: "it is a text and it has a table of contents" }\end{array}$ \\
\hline
\end{tabular}

Marinellie and Johnson [5].

Iranian Rehabilitation Journa 
Table 2. Categories and points assigned for the form of noun definitions

\begin{tabular}{|c|c|c|}
\hline Category & Point(s) & Example(s) \\
\hline Non-verbal & 0 & Pencil:\{demonstrates writing\} \\
\hline $\begin{array}{l}\text { Single word or article }+ \text { word } \\
\text { (no class term) }\end{array}$ & 1 & $\begin{array}{l}\text { Horse: "runs" } \\
\text { Baby: “a boy" }\end{array}$ \\
\hline Phrase/clause or simple sentence & 2 & $\begin{array}{l}\text { Train: "trains run on tracks." } \\
\text { Coat: "you wear" }\end{array}$ \\
\hline $\begin{array}{l}\text { Transitional form } \\
\text { (Use of "something" or "thing" plus attribute) }\end{array}$ & 3 & $\begin{array}{l}\text { Coat: "something you wear" } \\
\text { Book: "a thing that you read" }\end{array}$ \\
\hline $\begin{array}{l}\text { Partial Aristotelian form } \\
\text { [A kind of.....] [a (n).....] [a.....is a.....] [it's a.....] }\end{array}$ & 4 & $\begin{array}{c}\text { Horse: "a kind of animal" } \\
\text { Apple: "a fruit" } \\
\text { Train: "it's a type of transportation" }\end{array}$ \\
\hline $\begin{array}{l}\text { Aristotelian form } \\
\text { (Class term plus additional attribute) }\end{array}$ & 5 & $\begin{array}{l}\text { Horse: "an animal that runs fast" } \\
\text { Mouth: "a body part you use } \\
\text { to chew" } \\
\text { Coat: "a type of clothing } \\
\text { you wear in the cold" }\end{array}$ \\
\hline
\end{tabular}

Marinellie and Johnson [5].

Iranian Rehabilitation Journal

more, despite the decline in the use of clausal, phrasal, and simple sentence responses with age, this class was the most frequent one in all investigated age groups. As per Table 6, using non-verbal $(\mathrm{P}=0.002)$ and singleword $(\mathrm{P}<0.001)$ responses significantly reduced with age; however, applying full-Aristotelian definition significantly increased with aging $(\mathrm{P}<0.001)$. The changes in the transitional form were significant $(\mathrm{P}=0.029)$. Although changes have been observed in other responses, they were not significant.

The mean scores of form and content aspects were compared in the studied age groups. According to Tables 7 and 8, there was a significant difference in their mean scores $(\mathrm{P}=0.001)$. Such data indicate that the word definition's mean scores of form and content aspects increased with age. The multiple comparison method was employed to verify the exact differences between the content and form aspects per age group. Additional test results comparing the mean scores of the content and form aspects for three age groups suggested significant differences between the first and the second $(\alpha=0.05)$, as well as between the first and the third groups $(\mathrm{P}<0.05)$; however, no significant difference was observed between the second and third age groups in this regard.

\section{Discussion}

The current research data regarding the content aspect of word definition signified that the frequency of error responses decreased with age in the study participants. Providing error responses may indicate that the child is still experiencing setting and completing the process of word definition (slow mapping), and /her word knowledge is incomplete. This is a long process in which children always make hypotheses about the meaning of a new word. In this process, one is always modifying and updating the semantic representations and concepts related to the term until a thorough knowledge is obtained [17]. Using error responses significantly decreased with age in the study subjects; thus, the explored children's knowledge of the meaning of words was developing. For example, a child's failure to responding to the definition of a term may indicate that the child had inadequate knowledge regarding the definition of the word. When the child provided an incorrect response, like "We play at school" in defining a term, like "school", the response was similar to the definition provided for the word "park". As demonstrated in the present study, a five-yearold child is expected to provide a functional response in defining a concrete noun; however, the response mentioned above "we play at school" does not determine the school's function. Such a response indicates that the 
Table 3. The frequency of content-based responses of word definition in the examined age groups

\begin{tabular}{cccc}
\hline Age Groups & & No. (\%) & \\
\cline { 2 - 4 } Type of Responses & $\mathbf{5 4 - 6 5}$ Months & $\mathbf{6 6 - 7 7}$ Months & 78-90 Months \\
\hline Error & $23(4.76)$ & $9(1.83)$ & $323(64.28)$ \\
\hline Function & $357(71.03)$ & $353(72.65)$ & $39(7.73)$ \\
\hline Concrete & $60(11.70)$ & $29(5.91)$ & $1(0.19)$ \\
\hline Association & $6(1.19)$ & $4(0.81)$ & $4(0.79)$ \\
\hline Relation & $3(0.59)$ & $9(1.83)$ & $0(0)$ \\
\hline Synonym & $0(0)$ & $0(0)$ & $6(1.19)$ \\
\hline Class-nonspecific & $5(0.99)$ & $10(2.04)$ & $15(2.97)$ \\
\hline Class-specific & $9(1.78)$ & $16(3.26)$ & $26(5.15)$ \\
\hline Combination I & $13(2.57)$ & $20(4.08)$ & $83(16.46)$ \\
\hline
\end{tabular}

child is unaware of the school's primary function and that his/her knowledge of the school's meaning needs to be completed.

All of the study participants, regardless of age, presented a high tendency to provide functional responses. However, using functional and concrete responses decreased with age in the study subjects. Despite such declines, a majority of responses in the second and third age groups were functional, and no significant decrease was observed in this area. The decreased use of func- tional and concrete responses is predictable concerning the developmental process of word definition. Respecting the development process and Vygotsky's perspective, it is expected that children's maturity causes higher levels of awareness about word definition; they include the word into an opposition system beyond its concrete and functional features, assigning each word to a specific class and providing definitions that contain the word's class $[2,18]$. The increased use of specific and non-specific classes of words in preschool children of the second age group may be because of the same reason. The

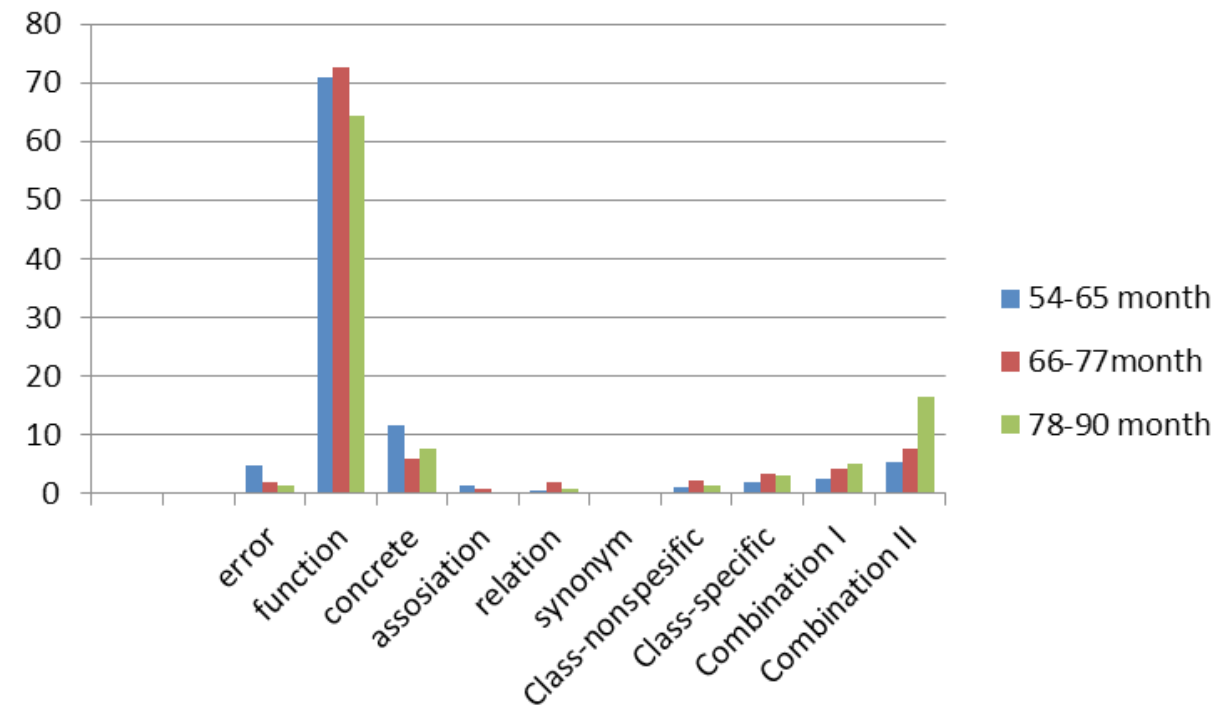

Figure 1. The frequency of content-based responses of word definition in the studied age groups 
Table 4. The frequency of form-based responses of word definition in the studied age groups

\begin{tabular}{|cccc|}
\hline \multirow{2}{*}{$\begin{array}{c}\text { Age Group } \\
\text { Type of Responses }\end{array}$} & $\mathbf{5 4 - 6 5}$ Months & No. (\%) & 78-90 Months \\
\cline { 2 - 4 } & $23(4.76)$ & $9(1.83)$ & $6(1.19)$ \\
\hline $\begin{array}{c}\text { Non-verbal } \\
\text { Single word or } \\
\text { article + word }\end{array}$ & $24(6.74)$ & $25(5.10)$ & $8(1.58)$ \\
\hline $\begin{array}{c}\text { Phrase/clause or } \\
\text { simple sentence }\end{array}$ & $302(59.92)$ & $253(51.63)$ & $263(52.18)$ \\
\hline $\begin{array}{c}\text { Transitional form } \\
\text { Partial Aristotelian } \\
\text { form }\end{array}$ & $112(22.22)$ & $155(31.63)$ & $125(25.59)$ \\
\hline $\begin{array}{c}\text { Aristotelian form } \\
\text { (class term plus Additional attribute) }\end{array}$ & $7(1.38)$ & $10(2.04)$ & $15(2.97)$ \\
\hline
\end{tabular}

Iranian Rehabilitation Dourna

Table 5. Results of content-based responses in the examined age groups

\begin{tabular}{ccccc}
\hline Variable & Age Group & Mean \pm SD & Z & P \\
\hline & $54-65$ months & $18.41 \pm 8.97$ & & \\
Content aspect of word definition & $66-77$ months & $21.14 \pm 7.99$ & 14.86 & \\
& $78-90$ months & $26.33 \pm 1.08$ & \\
\hline
\end{tabular}

Iranian Rehabilitation Џourna

frequency of these responses also decreased with age in the study participants. It seems that the definition of the specific and non-specific classes has changed to the combinations types I and II in older children. Providing definitions with a substantial and fluent form requires practice [19], and the school's official training provides such facilities. Moreover, schools might have contribut- ed to the increased use of the combination of types I and II in children. What assists children to explore their environment in the early years is the manipulation of objects and their function. Therefore, the function is the objects' main feature in the early years; it plays a more significant role than the language in shaping the child's concepts [20]. This is perhaps due to the importance of functions

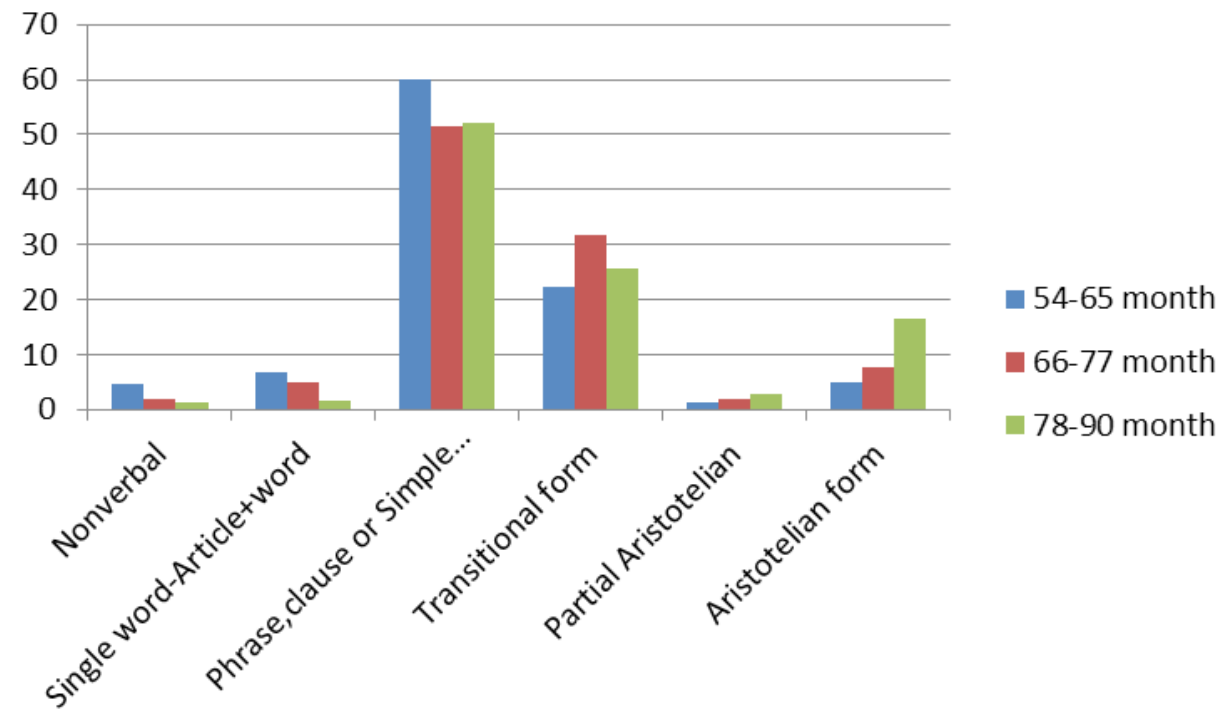

Figure 2. The frequency of form-based responses of word definition in the explored age groups

Iranian Rehabilitation Journal 
Table 6. Results of form-based responses in the studied age groups

\begin{tabular}{|c|c|c|c|c|}
\hline Variable & Age Group & Mean士SD & z & $\mathbf{P}$ \\
\hline \multirow{3}{*}{$\begin{array}{c}\text { Form aspect of word } \\
\text { definition }\end{array}$} & 54-65 month & $31.30 \pm 8.43$ & \multirow{3}{*}{12.10} & \multirow{3}{*}{0.002} \\
\hline & $66-77$ month & $35.02 \pm 8.21$ & & \\
\hline & $78-90$ month & $38.77 \pm 9.54$ & & \\
\hline
\end{tabular}

Iranian Rehabilitation Journal

Table 7. Changes in the content-based responses in the investigated age groups

\begin{tabular}{|ccc}
\hline Types of Responses & $\mathbf{Z}$ & $\mathbf{P}$ \\
\hline Error & 13 & 0.0001 \\
\hline Function & 2.006 & 0.367 \\
\hline Concrete & 11.73 & 0.003 \\
\hline Association & 3.45 & 0.178 \\
\hline Relation & 3.87 & 0.144 \\
\hline Class-nonspecific & 2 & 0.368 \\
\hline Class-specific & 2.15 & 0.341 \\
\hline Combination I & 4.305 & 0.116 \\
\hline Combination II & 36.40 & $>0.001$ \\
\hline
\end{tabular}

Пranian Rehabilitation Dournal

in forming the concepts. These data suggest that the reduced use of functional responses was not significant during the development process; the children of each age group also tended to adopt functional responses. The reason for not using synonyms by children may be the words used in the task, i.e. objectives, and no synonyms could be found for most objectives.

The current research findings were consistent with those of other studies in terms of word definitions adopted in different languages. To et al. [8] examined the development of definitions for objective terms in Chinese children. Their findings indicated that preschool children tend to employ more concrete and functional specifications to express definition. At the age of 7 years, definitions reflect the hierarchical nature of nouns. Using the class name begins at this age. At the age of 9 years, a greater portion of definitions comprise the name of the class, and the definitions are quite similar to those of the 11-year-old children.

Gavriilidou argued that functional and concrete responses used by the Greek preschool children shift to- wards more abstract responses, containing the class name with age. However, the functional responses remain the most frequent at this age $[7,8]$.

Concerning the responses with form dimension, using non-verbal responses and single-word transition significantly decreased with age, while using full-Aristotelian responses significantly increased in the study subjects. These findings were consistent with those of studies on the word definition conducted by Marinellie and Johnson [3, 5], Gavriilidou [7], and To et al. [8].

In the case of transitional forms, consistent with the findings of Marinellie and Johnson [5] and To et al. [8], the frequency of the responses was initially increased, then decreased with age in the third age group (78-90 months). In their studies, using transitional responses increased at the age of 9-10 years, and decreased after that. In the current study, applying such responses gradually decreased at the age of 6.5 years. This data discrepancy may be due to the different lexical categories used in the studies. The age of reaching a specific class seems to be affected by the lexical issues. In their studies, the chosen 
Table 8. Changes in the form-based responses in the studied age groups

\begin{tabular}{ccc}
\hline Types of Responses & $\mathbf{Z}$ & $\mathbf{P}$ \\
\hline Non-verbal & 13 & 0.002 \\
\hline Single-word & 15.61 & $<0.001$ \\
\hline Phrase/clause or simple sentence & 4.91 & 0.086 \\
\hline Transitional form & 7.1 & 0.029 \\
\hline Partial Aristotelian form & 3.06 & 0.216 \\
\hline Aristotelian form & 38.06 & $<0.001$ \\
\hline
\end{tabular}

words, e.g. "fan" as cooling equipment or "pencil" and "ruler" as stationery, were challenging for a child to attribute to a specific category. Thus, the child used the ambiguous word "something" to describe these words. As a result, the reduced use of transitional responses or ambiguous terms, containing a phrase occurs later.

The girls of the studied age groups used full Aristotelian forms more than their boy counterparts; however, the frequency of response was almost the same in both genders of the third age group. Such similarity might arise from the effect of formal education and the development of metalinguistic awareness. To define the Aristotelian form, a child must properly combine the semantic content in mind. Such a process requires meta-linguistic knowledge and the practice of the desired form, i.e. enhanced with age. Furthermore, schooling appears to be another factor contributing to this issue $[3,19,21]$.

Lack of significant changes in applying the function, association, relation, synonym responses, non-specific class, combination type I, clause, phrase, simple sentence, and partial Aristotelian form may be because of the slow development of word definition [7]. The increased mean score of the content aspect suggests that children use the definitions of higher quality to a greater extent (definitions achieved higher scores according to Table 1).

In terms of form, the child uses partial- and full-Aristotelian forms instead of a single word or phrase over time to express the semantic content in mind. In Persian, however, most children tend to use a specific issue with a descriptive phrase to build the full-Aristotelian form. As a result, there is a low frequency of partial-Aristotelian form in this regard.
Moreover, this increase results from the alternations in the development process of organizing words in the mental lexicon. This reflects that one has acquired the hierarchically-organized conceptual system [22]. According to Vygotsky, this system is of a certain length, suggesting that movements occur from introductory levels to more complex ones. The hierarchy also has a certain width, since it contains materials based on concrete properties and cases, like the names of the classes or categories never experienced by children. For example, for the word "horse" in this hierarchy; there are both tangible features, such as fast running, having a mane, as well as the superordinate term of the animal. Accordingly, it is expected that using specific terms in definitions of a child would increase $[2,7]$.

When defining a term, the child can move from one level to another in this hierarchy. If the child uses the sentence "It runs fast" to define the word" horse", he/she has expressed low levels of hierarchy; however, if he/she uses the sentence "It is an animal", he/she has reached higher levels of the hierarchy. Furthermore, the child's meta-linguistic awareness has also improved, and schooling provides him/her with the opportunity to practice the desired definition of the term to use the language structures to express the semantic content of their own [23, 24].

\section{Conclusion}

The present study results revealed that the development of word definition skill in Persian is similar to that of other languages. This similarity may be because of the words used in the test, i.e. all concrete. As external representations and semantic features forming the meaning of the objective words are alike in different languages; this similarity in the development process of the word definition skills may only be used for the objective, but 
not abstract nouns. Linguistic or cultural differences are involved in forming definitions for abstract words. Besides, there is less overlap in different languages between the definition of these words [25]; thus, generalizing the obtained data to other lexical classes might require further studies in this area, including applying words, such as abstract names, verbs, and adjectives.

The current study findings can be considered as a preliminary investigation to assess the word definition skill in children with language problems in this age group; subsequently, such measures provide them with educational and treatment solutions as long as such standardized tests are developed and standardized scores are obtained.

In this study, due to time constraints, it impossible to study a larger sample size from different districts in Tehran. Another limitation of this research was the task words, which included only objective but not abstract names and other lexical classes, including verbs and adjectives.

\section{Ethical Considerations}

\section{Compliance with ethical guidelines}

This study was approved by the University of Social Welfare and Rehabilitation's Ethics Committee. Before administering the word definition task, written informed consent was obtained from parents' children.

\section{Funding}

This study was approved and funded as a research project No. 1117 by the Research Deputy of Tehran University of Social Welfare and Rehabilitation Sciences.

\section{Authors' contributions}

Conception, collection of data, data analysis, interpretation of data and wrote the text: Maryam Malakian; Conception- supervised all stages of the article and final approval: Talie Zarifian; Drafted the original manuscript, and revising: Robab Teymouri; All authors reviewed the final draft of this article and agreed to submit the final version of the manuscript.

\section{Conflict of interest}

The authors declared no conflict of interests.

\section{Acknowledgments}

All authors would like to express their gratitude to the Research Deputy and Dr. Mehdi Dastjerdi Kazemi for their valuable guidance and Mrs. Masume Basi for her contribution in performing the final task used in this study. We also appreciate all children and parents who participated in this stud y.

\section{References}

[1] Astell AJ, Harley TA. Accessing semantic knowledge in dementia: Evidence from a word definition task. Brain and Language. 2002; 82(3):312-26. [DOI:10.1016/S0093-934X(02)00021-4]

[2] Luria AR. Language and cognition. [Ghasemzadeh H, Persian trans.]. Tehran: Arjmand Press; 1996.

[3] MarinellieSA, Johnson CJ. Adjective definitions and the influence of word frequency. Language, Speech, and Hearing Services in Schools. 2003; 46(5):1061-76. [DOI:10.1044/1092-4388(2003/084)]

[4] Nippold MA. School-age children and adolescents: Norms for word definition. Language, Speech, and Hearing Services in Schools. 1995; 26(4):320-5. [DOI:10.1044/0161-1461.2604.320]

[5] Marinellie SA, Johnson CJ. Definitional skill in school-age children with specific language impairment. Journal of Communication Disorders. 2002; 35(3):241-59. [DOI:10.1016/S00219924(02)00056-4]

[6] Nagy WE, Anderson RC. Metalinguistic awareness and literacy acquisition in different languages. Technical report. Champaign: University of Illinois at Urbana-Champaign; 1995. https://files. eric.ed.gov/fulltext/ED391147.pdf

[7] Gavriilidou Z. The development of word definitions in Greek preschoolers [Internet]. 2008 [Updated 2008] Available from: https:/ / www.ling.ohio-state.edu/ICGL/proceedings/9_GAVRIILIDOU_KEDITED_88.pdf

[8] To CKS, Stokes S, Man Y, T'sou B. An analysis of noun definition in Cantonese. Language and Speech. 2013; 56(Pt 1):24-105. [DOI:10.1177/0023830912440794] [PMID]

[9] McGhee-Bidlack B. The development of noun definitions: A metalinguistic analysis. Journal of Child Language. 1991; 18(2):417-34. [DOI:10.1017/S0305000900011132] [PMID]

[10] Mohammadi M, Shirazi TS, Nilipoor R, Rahgozar M. [Examining expression of lexical categories in Farsi- speaking Children with specific language impairment (Persian)]. Speech and Language Pathology. 2013; 1(1):8-19. https://www.magiran.com/ paper/1456800?lang=en

[11] Mohammadi M, Nilipoor R. Different categorization skills in SLI and normal children. SLI-Specific Language Impairment: Diagnosis, Prognosis \& Intervention, International Conference. 5-8 September 2012; Poland: Warsaw.

[12] Mohammadi M, Nilipoor R, Shirazi TS, Rahgozar M. [Semantic differences of definitional skills between Persian speaking children with specific language impairment and normal language 
developing children (Persian)]. Journal of Rehabilitation. 2011; 12(2):48-55. http://rehabilitationj.uswr.ac.ir/article-1-886-en.html

[13] Kikas E. The development of word definitions in children. Journal of Russian \& East European Psychology. 1993; 31(2):40-54. [DOI:10.2753/RPO1061-0405310240]

[14] Zarifian T, Matloubi S, Shirazi T S, Bakhshi E. Word definitional skills in school age Persian speaking children: A developmental study on form. Iranian Rehabilitation Journal. 2015; 13(3):103-8. http:/ / irj.uswr.ac.ir/article-1-558-en.html

[15] Firoozabadi A, Imani Jajarmi H. [Social capital and socioeconomic development in tehran's 22 municipal districts (Persian)]. Social Welfare Quarterly. 2007; 6(23):197-224. http://refahj.uswr.ac.ir/article-1-1968-en.html

[16] Watson R. Towards a theory of definition. Journal of Child Language. 1985; 12(1):181-97-. [DOI:10.1017/ S0305000900006309] [PMID]

[17] Chan Y-L, Marinellie SA. Definitions of idioms in preadolescents, adolescents, and adults. Journal of Psycholinguistic Research. 2008; 37(1):1-20. [DOI:10.1007/s10936-007-9056-9] [PMID]

[18] Benelli B, Belacchi C, Gini G, Lucangeli D. To define means to say what you know about things': The development of definitional skills as metalinguistic acquisition. Journal of Child Language. 2006; 33(1):71-97. [DOI:10.1017/ S0305000905007312] [PMID]

[19] Snow CE, Cancino H, De Temple J, Schley S. Giving formal definitions: A linguistic or metalinguistic skill. Language Processing in Bilingual. 1991; 115(2):90-112. [DOI:10.1017/ CBO9780511620652.007]

[20] Nelson K. Concept, word, and sentence: Interrelations in acquisition and development. Psychological Review. 1974; 81(4):267-85. [DOI:10.1037/h0036592]

[21] Gutierrez-Cleflen VF, DeCurtis L. Word definition skills in Spanish-speaking children with language impairment. Communication Disorders Quarterly. 1999; 21(1):23-31. [DOI:10.11 77/152574019902100104]

[22] Litowitz B. Learning to make definitions. Journal of Child Language. 1977; 4(2):289-304. [DOI:10.1017/ S0305000900001665]

[23] Walker SJ. Cognitive, Linguistic, and social aspects of adults' noun definitions. Journal of Psycholinguistic Research. 2001; 30(2):147-61. [DOI:10.1023/A:1010325811939] [PMID]

[24] Skwarchuk SL, Anglin JM. Expression of superordinates in children's word definitions. Journal of Educational Psychology. 1997; 89(2):298-308. [DOI:10.1037/0022-0663.89.2.298]

[25] Kroll JF, Sunderman G. Cognitive processes in second language learners and bilinguals: The development of lexical and conceptual representations. In: Doughty CJ, Long $\mathrm{MH}$, editors. The handbook of Second Language Acquisition. New Jersey: Blackwell Publishing Ltd; 2003. [DOI:10.1002/9780470756492] 
This Page Intentionally Left Blank 